\title{
Motivation of forming professional competences of students in the field of energy saving
}

\author{
Yana Zolotukhina ${ }^{1, *}$, Tatyana Makarova ${ }^{1}$, Sergey Dakhin ${ }^{1}$, and Ekaterina Prokshits ${ }^{1}$ \\ ${ }^{1}$ Voronezh State Technical University, Moscovskiy prospect, 14, Voronezh, 394026, Russia
}

\begin{abstract}
Now one of the most important factors of social and economic development of Russia is education that is dictated by shortcoming of competent professionals of the corresponding profile of society. Improvement of quality of training of students in the system of technical education in general and in the field of energy saving plays not the last role in strengthening of intellectual potential of the country. For increase in motivation of students several methods and the technician allowing to increase considerably the level of interest of students subject and field of activity have been analyzed and offered.
\end{abstract}

\section{Introduction}

Modern psychologists and teachers I focus the attention that the quality of performance of product and result, first of all, depends on poduzhdeniye and needs of the person, more precisely than his motivation. The motivation causes the activity directed to achievement of the goal, defining receptions and methods for achievement of the desirable. For any activity: communication, work or knowledge, motivation is "the zapuskny mechanism".

In the conditions of higher educational institution development of identity continues, gaining sensibleness and depth in understanding of the further implementation. And one of fundamental tasks of teachers of higher education institutions is in that psychology and pedagogical conditions on development of potential of the student have been created, to help students with forming of their motives and requirements.

Activity in the industry of energy saving is characterized by the high level of innovations, strengthening of integration of labor functions. The significant place is allocated energy saving system and to decrease in energy costs. Further development of the industry is not possible without participation of the specialists ready creatively and quickly to solve the tasks set for it, to effectively use the professional potential, it is rational to organize productions, to motivate and interest people around.

Personnel problem, according to bodies of supervision of efficiency of consumption of power and energy resources, their suppliers and consumers, is the main problem on the way of successful implementation of state policy in the field of energy saving. The main and indirect forms manifestations of this problem are:

- lack or total absence of guidance system of the enterprises of special department and the specialists creating and realizing to the politician of increase in energy saving;

${ }^{*}$ Corresponding author: yana_zolotuhiny@mail.ru 
- weak coherence of actions between masters, engineers and the management of the enterprise for questions of efficiency of energy consumption;

- most of the specialists working at the enterprise do not perceive power consumption of production processes, goods and services as one of the most important characteristics of the enterprise;

- the modern system of training of administrative personnel in the field of energy saving is far from perfect.

For modern power the professionals of large-scale of qualification formed and possessing wide range of competences, able to be guided in flow of new information capable quickly and accurately to solve difficult production tasks under constantly changing conditions are required. However the personnel structure of the heat power enterprises points to the shortage of the necessary number of skilled workers [1,2-4].

The lack of necessary number of competent specialists is looked through in all spheres of heat power area.

The solution of this problem demands significant change of system of training of students of the technical colleges studying in the field of energy saving.

Objective criterion of training of specialists in higher education institution is compliance of the gained knowledge, abilities and professional skills to requirements of potential employers. In most cases, higher education institutions when training students of engineering profile rely only on the state educational standards. However, today, one of burning issues is the discrepancy of the let-out specialists to those requirements which are imposed to them by production $[1,3]$.

It is connected with the following reasons:

- requirements of educational standards do not conform to requirements imposed to graduates by the enterprises employers;

- the existing restriction of standard times when studying professional disciplines in higher education institution;

- use of traditional forms and methods of training;

- the enterprises employers do not exercise intermediate control of real knowledge, skills (competences);

- lack of situational trainings for psychological adaptation of pupils to working and educational environment of higher education institution.

\section{Materials and methods}

For increase in motivation of students several methods and the technician allowing to increase considerably the level of interest of students subject and field of activity have been analyzed and offered. First of all the organization and conducting educational process has to be based on the principle of the "active training" directed to every possible activation of educational cognitive activity of students by means of wide complex, uses both pedagogical (didactic), and organizational and administrative means. The teacher acts as the mentor (tutor) here, and training is concentrated directly around the student. For the organization of interaction of the head and collective project-oriented educational programs integration of BIMcloud service is reasonable. BIMcloud is the decision allowing to organize full BIM interaction of the working collectives participating in development of projects, any sizes at any configurations of networks and the equipment [5-8]. 


\subsection{Technique of training of specialists in the field of energy saving in English using method of "active training"}

In many higher education institutions including in VGTU, maintaining disciplines in English practices. Not always students are native speakers of English. Therefore for the teacher sharply there is question how to interest and help students with studying of disciplines of construction orientation and also technical English. Thus, it is reasonable to integrate technique of "active training" and its basic principles into teaching disciplines in English as the second or foreign that in turn will help students to tighten level of proficiency in English in parallel with studying of basic course [9-10]. The technique of ESP (English for specific purposes) - English for the special purposes which is based on the specialized lexicon and skills necessary for studying of disciplines of course enters basis of teaching such disciplines. Approach to training is based on team immersion of students in studying not only the subject, but also directly on improvement of level of English.

The represented technique is symbiosis of studying of technical disciplines of the program of magistracy and foreign language (in this case English). At the same time at the initial stage there is forming of teams of students who in the subsequent are engaged in development of the project directly in English [11]. This approach allows not only to realize the potential of each student, but also gives them the chance to show and apply the abilities, knowledge and skills in specific situation. Forming of teams happens taking into account specific features and level of knowledge of students. Students are forced to take active and long part in the project, but not incidental, the involvement of everyone into studying of materials of discipline thereby increases.

At the initial stage testing of students is held and the level of proficiency in English is defined. Based on these data teams on 3-4 persons are formed. In team students integrate with different level of proficiency in English, for example: one student with level "above average" and three students with level "average". Such teams are formed within one discipline, is admissible to leave the same team's line-up for other disciplines taught in parallel. Certain situation which demands carrying out the analysis and also developments of versions of its decision [12] is offered to teams. Team work is resulted by indirect mutually training of participants as directly to discipline subject, and English.

The teacher is recommended to build the class in the following scheme:

1) Introduction - short digression to scope of occupation;

2) Warm-up - training of students for perception of the subsequent material of subject. Warm-up options: acquaintance (is suitable for the first occupation); brainstorming - in group or couples; "make words" - the game for warm-up allowing to repeat terms in English on scope of occupation; game on comparison of terms to definitions.

3) For simplification of perception of new terms it is necessary to prepare keywords on subject of occupation in advance and to write them on board. During the occupation definition should hold the game "Alphabet" or comparison of the term it, for example, in couples.

4) Statement of new material - is preferable use visual online of the presentations, video. Using, for example, Nearpod service which allows to develEP the multimedia lessons containing audio-and video files, text and illustrative material, various interactive resources - quizzes, video, polls, instruments of drawing and many other things and also to load ready lessons of the colleagues teachers from the website Nearpod [13]. In turn pupils can take notes and drawings, and then to export them on the teacher's device; to answer questions in different formats, including in the form of the text and the added images; to look through the presentations at own speed; to receive multimedia content from the teacher and to participate in assessment of team work of group. For maintenance of communication with audience and improvement of digestion of material it is offered to conduct surveys on the stated material, using the kahoot.com resource (Figure 1) [14]. Thanks to this service 
assessment of answers of students is displayed by resource immediately. Direct feedback enhances the involvement of students. Website Kahoot advantage! opportunity to keep the received results for the further analysis teachers is. It allows to review maintenance and representation of training material the next academic year for the purpose of increase in its assimilation by students. Besides, the received results can be used for deeper studying of the concepts and sections which have caused difficulties in students.

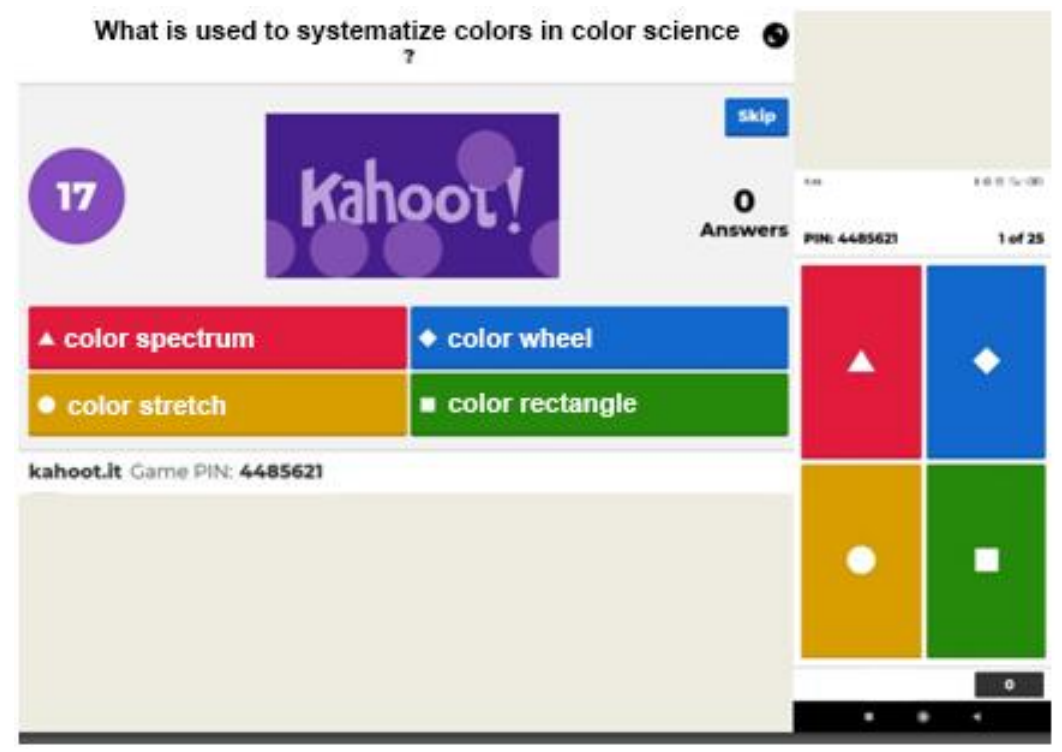

Fig. 1. Exterior of the website Kahoot! and the student's smartphone with the installed application.

5) Practical work - is directed to work of students in team. The motivation of students as the executed project, but not just assessment is result of training is establishing here. Working in team there is indirect mutually training of participants as directly to discipline subject, and English.

6) Feedback with students - at the end of occupation is recommended to conduct survey of students. Two or three questions, for example, that was unclear on occupation or what questions have been taken insufficiently up. It will help the teacher to consider opinion of students and also to open the questions interesting them in more detail that will increase interest of students.

It is reasonable to carry out the assessment of knowledge of English together with control of the acquired material on taught discipline at the end of educational semester. One of evaluation stages of students is testings. The contents of tests correspond to materials of course and are made in English that allows to define level of proficiency in foreign language and also to monitor personal progress of each student. It is supposed that as a result the group of students has to improve the knowledge of foreign language to levels three of group "the high level", one "advanced". On the basis of these data the further regrouping of teams by the same principle is possible. The following stage is the presentation and justification of one of versions of the solution of problem-oriented situation. The done work in team allows to allocate roles of each participant in the project and to place emphasis on abilities and features of each student. Also teams estimate result of each other that allows to analyze once again the done work from other position (for example, not the designer of the project, but the customer). 


\subsection{Technique of training of specialists in the field of energy saving by means of integration of BIMcloud}

The GRAPHISOFT company in ARCHICAD has implemented team work (TEAMWORK) which cornerstone the BIM Server allowing to cast flexibly users in projects and to appoint to them access that provides the high level of safety of work is. Installation of the BIM server is made and team work is organized that allows teachers to control the course of implementation of the project, and to students to have access to BIM projects in considerable remoteness.

At implementation of this method norms and standards of educational programs and projects, one of which is GOST P ISO 21500-2014 [15], form basis. This standard contains the general recommendations, the basic concepts and characteristics of processes of design management which are important for implementation of projects and affect their results.

There is huge number of definitions of the term "project" which come down in the standard standards on project management. It is possible to look at the main standards (guides) to project management on Figure 2.

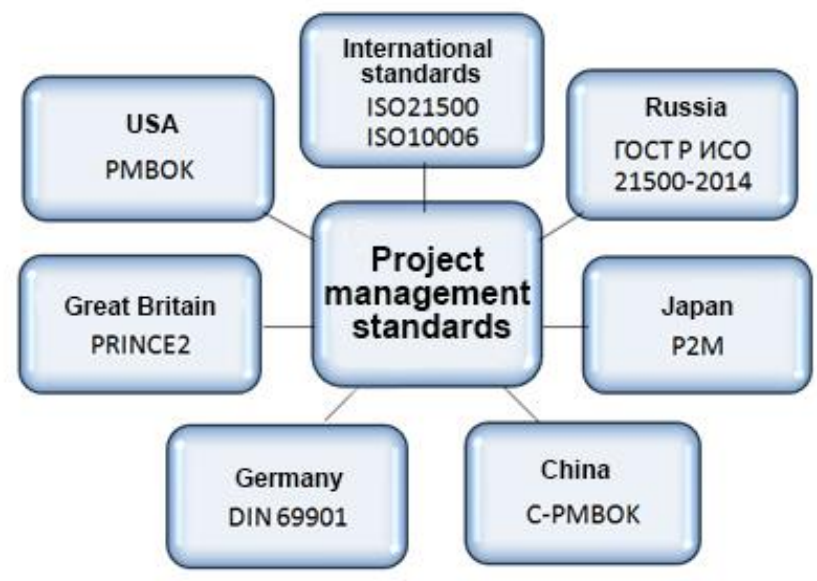

Fig. 2. Standards (guides) to project management.

According to the Provision on research and design activity of students of VGTU general provisions are revealed:

1.Design activity (student's projects) - the separate type of educational activity of students within the educational program (further EP) assuming special forms of the organization and monitoring procedure.

2. Obligatory part of design activity which the student is obliged to execute on the terms of OP, and the variable part assuming the free choice of projects from the special catalog of student's projects can be enshrined in the curriculum of EP.

3. The offer and the choice of projects are carried out by means of the uniform University of the mechanism of initiators and potential participants of projects implemented in the form of the special section "Catalogue of Projects" on VGTU website.

4. "The catalog of projects" is open for placement of design requests and the choice of projects for academic year (Figure 3) [16]. 


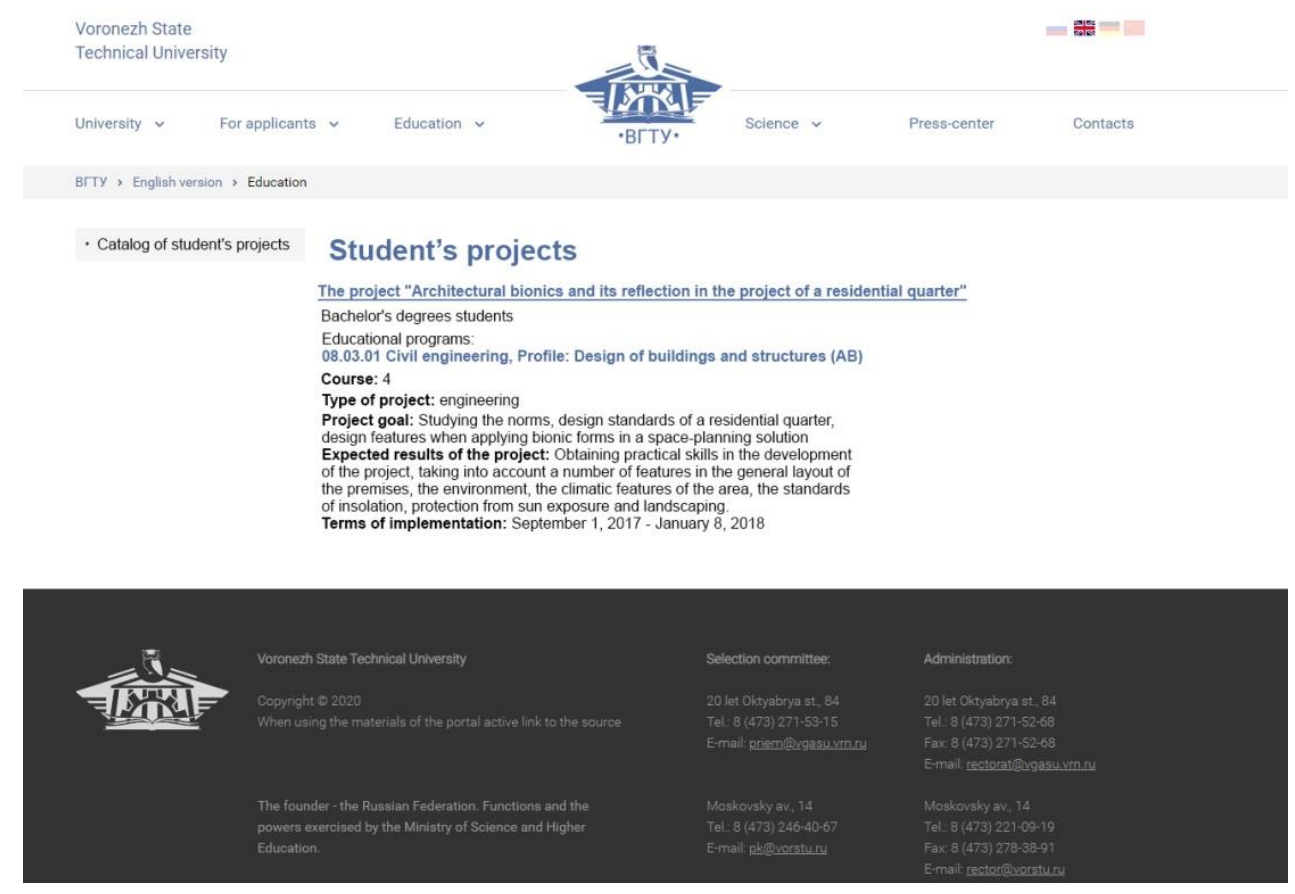

Fig. 3. Catalog of student's projects. Screenshot with office of the website of VGTU.

5. The module of design activity in the curriculum of training of students is oriented to use of knowledge, the skills received during training for statement and the solution of the practical tasks including demanding collective work of students including interfaculty [17]. At the same time tasks can carry both the academic, and applied character. In design and research all types of competences of students form: common cultural (universal), allprofessional, professional special, profile, etc. The EP this element has to join activity within research projects of the university, within projects of student's groups, course design, preparation of final qualification work and also practice.

On screenshot from the official site of VGTU (Figure 3) it is possible to see how "The catalog of student's projects" where it is possible to find all necessary information on the project, on the educational program according to which it is implemented, go type, the purposes and the expected results, all about terms and the head looks. Record on the chosen project can be made both online on the website, and personally.

Important trend is creation of the BIM model including models of different Sections [18]. At the same time it is impossible to force all participants of the project to work at one platform, and representatives of different specialties should resolve coordination issues.

BIMcloud acts $\triangle B I M-S e r v e r$ technologies on the basis and is completely scalable solution perfectly suitable for any working groups and projects of any sizes. (Figure 4) 


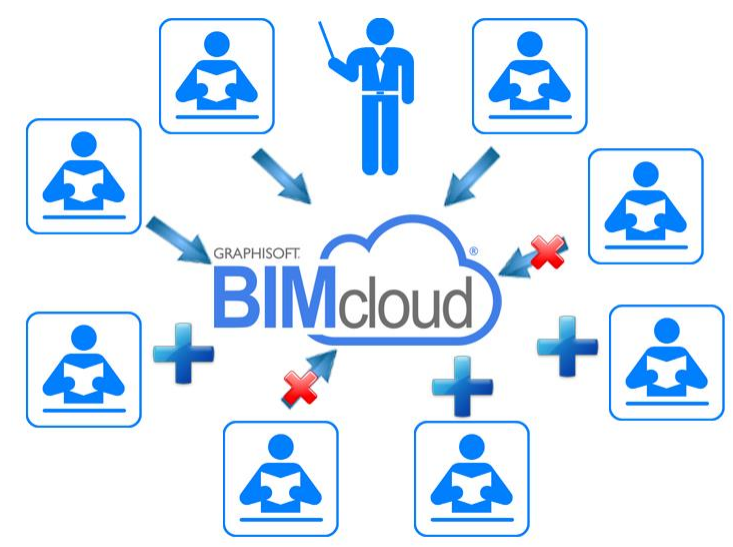

Fig. 4. The scheme of interaction of collective with BIMcloud.

BIMcloud allows to organize interaction with all participants of design in real time. Each participant can get access to all project documentation both from the Internet of the browser, and from any mobile device on which the BIMXpro application is installed. The BIM platform of interaction completely adapts to requirements of participants of design process (Figure 5).

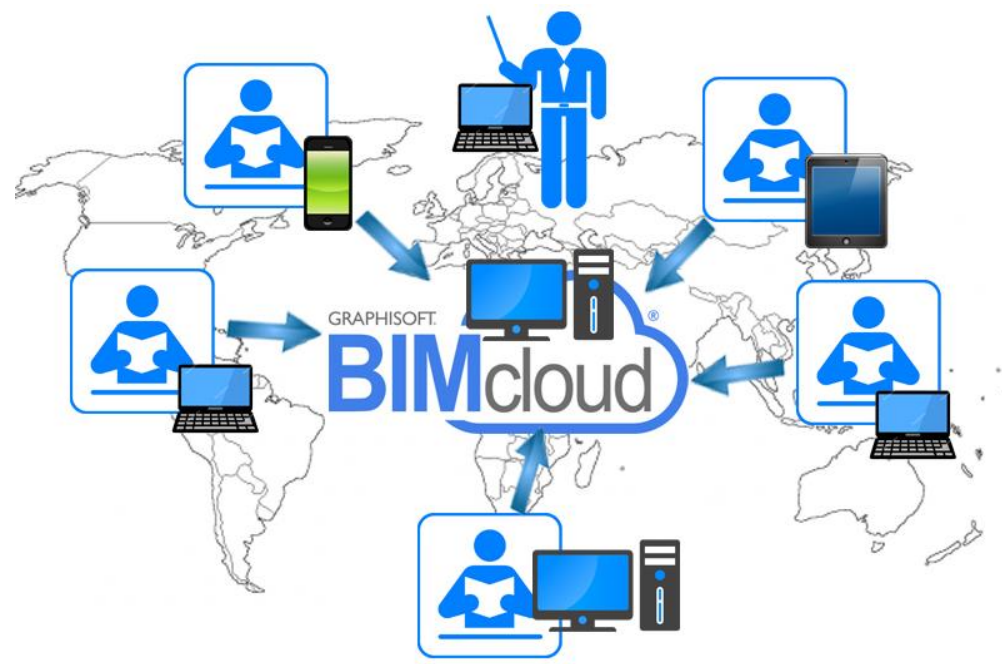

Fig. 5. The scheme of connection to the main server of participants of the project from devices with access to Internet network.

BIMcloud does not demand big additional expenses for additional program or the hardware. BIMcloud is integrated into corporate working environment, its control interface is separated from data of the project that will allow the head of group to adjust working environment of the project and to set restrictions and access for each of participants.

Team work allows to configure settings of roles for access to general settings of the project, general information about the project, communication with external data. During the work on difficult objects full access has to be provided only to specialists who understand structure of model of the project. 


\section{Results}

The main expected result of implementation of this method on motivation of forming of professional competences of students, forming of the flexible educational programs demanded by employers and oriented to the advanced production technologies, optimization of educational and methodical, material resources at implementation of project-oriented educational programs in the field of energy saving improving competitiveness of the University and demand of graduates in labor market is.

As a result of successful completion of training, students graduates will have sufficient knowledge and competences to represent the ideas and to implement projects at the international level. In the course of training, students will be able to develEP the projects in English that will allow them to participate in the international competitions and grants, representing the Higher Education Institution. Thereby, opening big possibility of exchange of experience and cooperation with other Higher education institutions of the world.

\section{Conclusion}

Current trends of design and information technologies in many respects set today's vector of training. One of them observes significant increase in volume of information in all fields of activity. As for projects, they become more volume, the increasing number of participants is involved in their creation. Thus, students need to have skills of team work as it not only considerably accelerates implementation of the project and facilitates coordination in design group, but also gives the chance to involve students of the different directions and specialties [19]. As a result it will allow to recreate the process close to real work of the design organization which includes itself set of sections and close interaction during the work on object that will increase considerably motivation of students.

Implementation of technique of "active training", Teamwork and BIMcloud in educational process of project-oriented training in the field of energy saving will allow to increase the level of projects. As the main part of term and project works during training has individual character, this technique of work on projects will help to gain skills of team work, first. Secondly, to get clear understanding of the function and the importance for the general productivity [20]. Similar work is the intermediate stage between educational and professional activity. What will allow to increase considerably level of training of graduates and to train the specialists of high level demanded in labor market.

\section{References}

1. Y. Jabareen, A New Conceptual Framework for Sustainable Development 10, 179-192 (2008)

2. DIN 69901-1-2009. Project management. Project management systems. Part 1. The Basics (2009)

3. Russian Federation Standard GOST R 54869-2011 Project management. Project management requirements (Standartinform, Moscow, 2011)

4. ANSI PMI PMBOK 5th Edition - Guide to the Project Management Body of Knowledge (PMBOK Guide)

5. ISO 21500: 2012 Project Management Guide (2012)

6. PRINCE2 (projects in a controlled environment)

7. P2M-"Project and Program Management Guide for Enterprise Innovation

8. S. Hamiti, H. Wydler, Sustainability 6, 3291-3300 (2014) 
9. S.P. Alvarez, K. Lee, J. Park, S.Y. Rieh, Sustainability 8 (2016)

10. J. Wright, Introducing Sustainability into the Architecture Curriculum in the United States 4, 100-105 (2003)

11. K. Warburton, Deep Learning and Education for Sustainability 4, 44-56 (2003)

12. A.Z. Khan, H. Vandevyvere, K. Allacker, Design for the Ecological Age: Rethinking the Role of Sustainability in Architectural Education (2013)

13. S. Altomonte, P. Rutherford, R. Wilson, Mapping the Way Forward: Education for Sustainability in Architecture and Urban Design 21, 143-154 (2014)

14. Z. Shari, M.F.Z. Jaafar, Towards a More Sustainable Architectural Education in Malaysia 1, 57-64 (2006)

15. Russian Federation Standard GOST R ISO 21500-2014. Design Example Guide (Standartinform, Moscow, 2015)

16. http://cchgeu.ru/upload/iblock/233/polozhenie-ob-upravlenii-i-realizatsiiproektno_orientirovannykh-osnovnykh-professionalnykh-obrazovatelnykh-programmvysshego-obrazovaniya.pdf

17. P.R. Berke, J. Kartez, Sustainable Development as a Guide to Community Land Use Policy (1995)

18. P. Healey, T. Shaw, Planners, plans and sustainable development, 769-776 (1993)

19. D.H. Meadows, D.L. Meadows, J. Beyond, Randers. Confronting global collapse, envisioning a sustainable future (1992)

20. J. Robinson, J. Tinker, Reconciling ecological, economic and social imperatives: $A$ new conceptual framework, 71-94 (1997) 